\title{
Problemas psicopedagógicos de la lengua oral: las lecciones de una experiencia
}

\author{
Daniel Bain
}

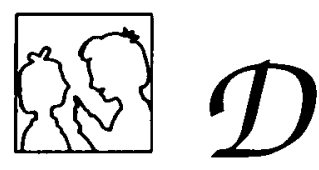

Diez años después, una secuencia didáctica a propósito de la enseñanza de la lengua oral sigue siendo de actualidad. A pesar del empeño y del entusiasmo de profesores e investigadores $y$, a pesar también de un dispositivo original - rodar un sketch en video -, la experiencia realizada para trabajar la argumentación oral con adolescentes de 13-14 años, no dió los frutos esperados. El autor nos ofrece un análisis detallado de este «fracasa» y nos indica algunas pistas pedagógicas que deberían seguirse, así como algunas pistas falsas que deberían ser abandonadas.

Como indica el título de esta contribución (la ausencia de artículo delante de Problemas), no tengo la pretensión de abordar todos los problemas planteados por la enseñanza de la lengua oral, ni tampoco estructurar o señalar la discusión sobre este tema. Me contentaré con plantear algunas preguntas inspiradas en una experiencia y, más concretamente, en la actividad de un grupo de profesores e investigadores que dirijo sobre el tema de la pedagogía del texto (en el sentido amplio que la lingüística da a este último término). Me parece importante, en este estado de la reflexión, no sólo sugerir algunas pistas didácticas, sino también señalar ciertas pistas falsas. Después de algunas observaciones a modo de introducción, presentaré la evolución y los resultados de una secuencia didáctica que tiene por objeto la argumentación oral. Incluiré en mi texto algunos comentarios ampliando el tema a los problemas encontrados en la enseñanza de la lengua oral más generalmente.

\section{INTRODUCCION Y PRESENTACION DE LA EXPERIENCIA}

\section{Un sentimiento de frustración}

Podría parecer sorprendente que vaya de nuevo a una investigación que tiene ahora más de diez años. Hay varias razones de ello.

En primer lugar, un cierto sentimiento de frustración. He dudado en dar como subtítulo a mi exposición: las lecciones de un fracaso. Profesores e investigadores que participamos en este experiencia, nos encontramos, en efecto, delante de la siguiente situación paradójica. Habíamos planificado una secuencia didáctica de 8 
lecciones: tenía como ambición mejorar las capacidades de alumnos de 14 años para argumentar oralmente, para presentar y defender la evaluación crítica de un video realizado por sus compañeros. Pretendía, muy especialmente, favorecer la interacción entre los alumnos de dos clases de $8^{\circ}$ y «liberar su palabra». Sin embargo, en la tercera sesión, todos los alumnos se negaron a hablar e hizo falta una intervención incisiva de los profesores, surtida de amenazas ( « $\mathrm{Si}$ es así, vamos a hacer gramática u ortografía!») para desbloquear parcialmente la situación. Luego veremos las razones de una tal crisis, que se explican por la ingenuidad con la que abordamos - y seguimos abordando - la pedagogía de la lengua oral y las interacciones sociales que ésta implica.

Sentimiento de fracaso también porque al final de la secuencia, los progresos, a nivel de la argumentación oral, apenas fueron espectaculares, suponiendo que hubiéramos tenido los instrumentos adecuados para evaluarlos, y sobre todo, porque esos progresos solo lo eran de una minoría.

Frustración también porque esta investigación es uno de nuestros raros trabajos que ha sufrido una censura a nivel de su publicación, cuya difusión fue, debido a este hecho, entre otros, relativamente confidencial (Boget y cols., 1977; Bain y Hexel, 1977). No hablaría de este incidente si esta intervención de la autoridad escolar no estuviera relacionada directamente con uno de los aspectos y de los objetivos relacionados a menudo con la lengua oral y que recordamos al instante: la liberación de la palabra y de la expresión. En efecto, paradójicamente, los textos censurados no fueron los de los investigadores sino el resumen de las producciones de los alumnos. Se les reprochaba la representación de escenas de violencia.

En fin, en el momento en que la pedagogía del francés decide, en la Suiza de lengua francesa, interesarse más específicamente por la lengua oral, en nuestro equipo actual no disponemos de otra experiencia estructurada sobre este ámbito y que mereciera ser presentada. He aquí lo que confirma el diagnóstico realizado sobre todo por Perrenoud $(1988$, p.1) sobre los pocos e insuficentes trabajos relativos a este aspecto, pariente pobre del francés.

Precisemós que cuando hablamos anteriormente de fracaso, no se trata, para mí, de reprochar nada, aunque fuera indirectamente, a los maestros, protagonistas de esta secuencia; por otra parte, la responsabilidad de este trabajo fue compartida con los investigadores. Mediante esta exposición, desearía, al contrario, testimoniarles todo mi reconocimiento al haber osado avanzarse en un terreno poco explorado, aceptando correr riesgos, que, finalmente, se han mostrado provechosos a nivel de la investigación pedagógica. Si esta experiencia hubiera sido realmente una catástrofe, no hablaría de ella diez años después. Este «fracaso» tuvo, efectivamente, el gran interés de poner en evidencia una serie de fenómenos y de problemas relacionados con la pedagogía de la lengua oral, lo que justifica el informe y el análisis que haré. Es probable que una experiencia «con éxito» no nos hubiera aportado tanta información.

\section{Presentación de la secuencia didáctica}

Esta experiencia, concebida y realizada por dos profesores de francés del «Cycle d'orientation" ginebrino ${ }^{1}$, implicó y puso en contacto, a dos clases de $8^{\circ}$ (alumnos de 13-14 años): la primera, de sección Latino-Moderna (LM), rama que desemboca, en principio, en estudios en una escuela secundaria superior; la segunda, de sección General (G), que prepara para una formación profesional en la escuela o en un aprendizaje en un lugar de trabajo. 
Inspirándose en una experiencia realizada con anterioridad en la escuela primaria, los profesores habían previsto el siguiente dispositivo (Boget y cols., 1977, p. $1-8)$.

Ambas clases deben producir cada una de ellas cuatro sketchs filmados en video (tema libre), sketchs que veían juntas, ambas clases, a lo largo de la producción. Para ello, cada clase forma cuatro equipos de rodaje compuestos por cuatro a seis alumnos. En primer lugar, dichos equipos son iniciados en el manejo del video (dos horas). Al inicio de la experiencia propiamente dicha, durante una semana, un primer equipo en cada clase prepara, filma y ve su sketch. A la semana siguiente, las dos clases se encuentran durante dos sesiones de una bora para ver y criticar en común cada una de las dos producciones. Algunas semanas más tarde, la experiencia se lleva a cabo nuevamente con un segundo equipo, y asi sucesivamente basta el cuarto y último sketch de cada clase. Una parte de la última sesión de la secuencia se consagrará a realizar un breve balance de la experiencia.

La totalidad de la secuencia fue observada por dos colaboradores del Centro de investigaciones psicopedagógicas del «Cycle d'orientation»: Dagmar Hexel y Daniel Bain.

Se impusieron dos restricciones a cada equipo: el sketch debía ser mudo y no podía exceder de una duración de diez minutos. Dos condiciones favorables a la discusión que debía seguir, ya que limitaban el tema a las características de la imagen de video y a una producción restringida en su amplitud.

Los profesores se fijaron objetivos pedagógicos de tres órdenes:

1) «Aprendizaje de ciertas técnicas: utilización de una cámara, confección de un guión, realización de decorados, etc.

2) Familiarización con el mundo de la imagen: aprender a expresarse a través de imágenes, sin sonido; aprender a dominar mejor el lenguaje de la televisión reflexionando y discutiendo a propósito de imágenes.

3) Aprendizaje social: aprender a defender las ideas y a debatirlas, aprender a aceptar un punto de vista exterior al grupo de clase, etc.» (op.cit., p. 2).

Se observará de entrada que el objetivo didáctico «preparar para la argumentación oral» no se menciona explícitamente en esta lista. Efectivamente, está implícito en la situación y en ciertas etapas de la secuencia: toda la operación tiene lugar durante las clases de francés; la preparación para la argumentación figura en el programa de $8^{\circ}$, la forma oral puede ser considerada como propedéutica a la composición de ideas de $9^{\circ}$; el proyecto de la experiencia prevee sesiones regulares consagradas a la crítica en común de los sketchs. Por otra parte, el aprendizaje de la discusión o del debate, de la argumentación mediante la defensa de sus ideas se incluye en los objetivos 2 y 3 antes mencionados.

En principio pues, las adquisiciones que podrían hacer los alumnos en este ámbito participan probablemente, según los profesores, del aprendizaje incidental y espontáneo, especie de subproducto de otras actividades dirigidas a alcanzar objetivos primordiales diferentes. Me parece que es una concepción de la enseñanza de la palabra bastante extendida. Cuando se critica a los maestros de francés dedicar muy poco tiempo a la lengua oral, replican a menudo diciendo que lo hacen constantemente, a lo largo de las lecciones normales. Olvidan que durante la mayor parte de las clases, quienes hablan son ellos, y que las raras intervenciones de los alumnos no son objeto de un tratamiento didáctico. En el estado actual de nuestra enseñanza del francés, no es pues evidente, tomando las tesis de Perrenoud (op.cit., p. 3 y siguientes), que el dominio de la lengua oral sea un objetivo de pleno derecho, que un dominio de la lengua oral no se adquiere espontáneamente, o incluso que el dominio de la lengua oral sea específico (tesis 1, 2 y 4). En la experiencia que estoy comentando, no es sino más tarde cuando se verá la necesidad de un aprendizaje específico de la argumentación en tanto que medio discursivo indispensable para alcanzar los objetivos 2 y 3 antes mencionados. 
Se observará, en cambio, que los profesores promotores de la secuencia enfatizan desde el principio ciertos aspectos de la lengua oral que a menudo no entienden sus colegas (sigo refiriéndome a las tesis de Perrenoud). Consideran implícitamente el dominio de la lengua oral como una competencia práctica, (...) la lengua oral como un instrumento de comunicación en situaciones concretas, con posturas concretas: convencer, argumentar, negociar, explicar(se), informar(se) (tesis 3). En las fases de discusión, los miembros de los equipos productores recurrirán a la argumentación para defender, con una cierta energía, su sketch o sus intenciones; sus oyentes y espectadores utilizarán el intercambio oral para que se les expliquen ciertas escenas presentadas (no siempre muy explícitas), introducir propuestas o críticas y defenderlas, etc.

Dede el punto de vista de la perspectiva didáctica que defendemos en nuestro equipo, un verdadero debate, inherente a la situación, constituye la condición indispensable a cualquier secuencia didáctica relativa a la argumentación (cf. Commission Pédagogie du texte, 1988). Se lleva así a los alumnos a no hablar para no decir nada (tesis 8 ), las ocasiones de discurso motivado y pertinente son desgraciadamente demasiado raras en la escuela (sobre todo, en secundaria). En nuestro caso, las primeras sesiones de discusión eran tanto menos gratuitas, en la perspectiva de toda la secuencia, cuanto que el debate debía proporcionar elementos concretos de sugerencias para el rodaje de los siguientes sketchs. Los alumnos tenían que producir, pues, un texto (oral) que fuera a la vez informativo, explicativo, didáctico y argumentativo.

Como lo muestran los objetivos asignados a la secuencia, ambos maestros eran sensibles a los aspectos socio-afectivos, incluso sociológicos de la comunicación oral. Querían precisamente utilizar esta situación, en la que la imagen tenía un papel central, para dar la palabra a aquellos alumnos que no la tomaban fácilmente en los ejercicios habituales de la clase de francés; querían que comunicaran entre sí clases, cuya situación escolar (sección de pertenencia) tiende generalmente a separar, incluso a oponer. De hecho, otorgaron mucha importancia al tercer objetivo (aprendizaje social), cuya formulación, relativamente técnica y neutra, no reflejaba más que una parte de sus intenciones, como se dieron cuenta al final de la experiencia.

Me parece encontrar, en otros proyectos o experiencias relativas a la lengua oral, este mismo objetivo más global: mejorar la comunicación entre los alumnos - y sobre todo entre alumnos de diversas categorías sociales o escolares -, o más generalmente, mejorar la comunicación en la escuela; favorecer el hecho de compartir, valorizar e integrar mejor a los alumnos flojos, etc. (cf. Pasquier y Steffen, 1988, p. 6: Pratiquer l'oral, pourquoi?). ¿No se podría ver en ello, el resultado de un cierto sentimiento de culpabilidad por parte de los profesores en relación a la selección de la que son los agentes - volentes nolentes - en el resto de la actividad escolar?

\section{El dispositivo de observación del desarrollo de la secuencia}

No diré más que dos palabras para pasar rápidamente a los resultados de esta observación.

Nuestro dispositivo se centró en: a) la forma y la precisión de las evaluaciones emitidas por los alumnos sobre los sketchs; b) la participación de los alumnos en la discusión; las interacciones entre alumnos y clases.

Para llevar a cabo nuestros fines, utilizamos una grabadora unida a una serie de micrófonos por una mesa de mezcla de sonidos y una parrilla de análisis de doble entrada que permite a los dos observadores codificar las interacciones (¿quién habla a quién?): 
FiguRA 1

Parrilla de codificación de las observaciones

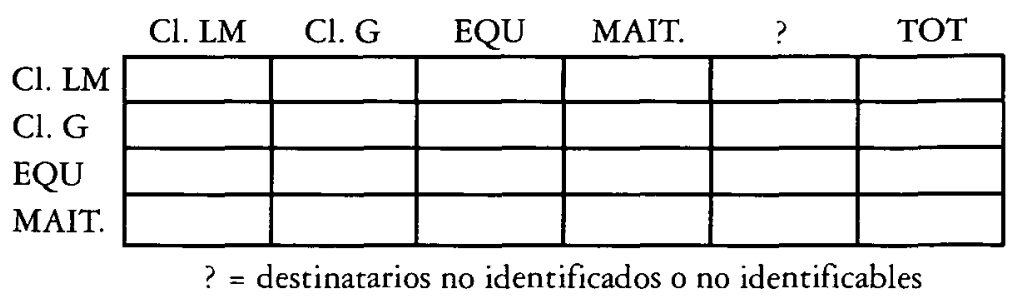

Como los maestros daban la palabra a los alumnos llamándoles por su nombre, pudimos anotar el número de intervenciones de cada uno de los participantes. Por otra parte, observamos la dirección de la comunicación entre los 4 grupos presentes: las dos clases, espectadoras y críticas hacia el sketch presentado al principio de la sesión. Ante ellos, el equipo productor del sketch que lo presentaba y defendía; a un lado, los profesores, que animaban y regulaban la discusión, y que se esforzaban en intervenir lo menos posible (figura 2).

FIGURA 2

Disposición de los actores de la experiencia

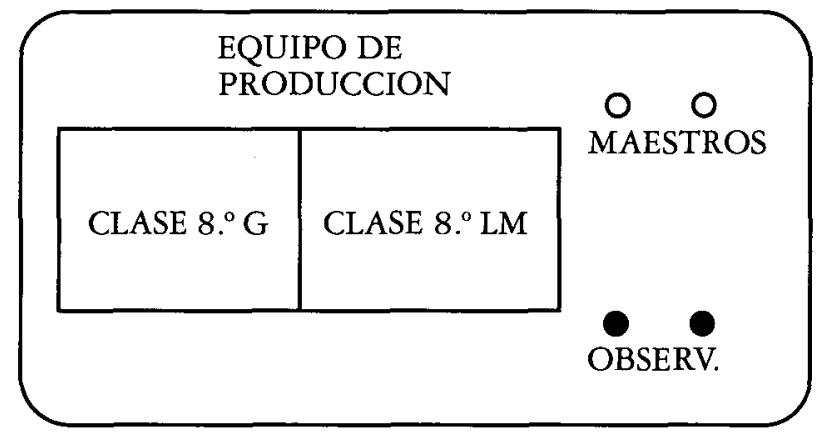

\section{RESULTADOS Y COMENTARIOS}

\section{El objeto de la actividad argumentativa y la motivación de los alumnos}

El principio mismo de una pedagogía eficaz (Bain y Schneuwly, 1987) requiere que se escoja como objeto de la secuencia didáctica un tema que motive a los alumnos, a propósito del cual tienen ganas, incluso necesidad, de expresarse y/o de comunicar con los demás, y, en el caso de la argumentación, que desemboca en un auténtico debate con algo verdadero en juego. Así fue en buena parte en la experiencia que observamos. Los alumnos se implicaron mucho tanto en el aprendizaje del video como en la producción del sketch. Se podía suponer que cada equipo estaría interesado en presentar el resultado de su trabajo y en defender su sketch. La discusión debía ser animada ya que los espectadores-críticos habían tenido - o tendrían - la oportunidad de preparar una cinta de video análoga, con los mismos problemas artísticos y técnicos.

Otra ventaja de la situación, desde el punto de vista didáctico, fue el hecho de que la actividad de lenguaje (la discusión) versaba sobre un objeto o un contenido poco familiar y no de lenguaje: la película muda y su preparación, y no un texto o una serie de textos, de los cuales, los alumnos hubieran podido sacar una parte de la 
formulación de sus intervenciones (cf. ejercicios como la argumentación a partir de textos polémicos o la evaluación crítica de producciones escritas). La discusión exigía que elaboraran el contenido o el objeto del debate, que adquirieran, a lo largo de la secuencia, los instrumentos cognitivos $y$ de lenguaje que les permitieran criticar o defender de manera adecuada un sketch en video: qué se puede criticar, qué criterios invocar (lógicos, estéticos, técnicos), cómo presentarlo, qué términos utilizar para expresarlo (nombres y adjetivos técnicos, expresiones de evaluación). De esta forma, se puede enseñar más fácilmente a los alumnos la intención funcional de los aprendizajes que están haciendo en el ámbito de la comunicación.

En el experimento «para ver qué pasaba», del cual damos cuenta, formulábamos, explícita o implícitamente, las hipótesis siguientes:

- los sketchs preparados libremente por los alumnos proporcionarían una base adecuada a la discusión;

- la totalidad de las actividades propuestas a los alumnos eran suficientemente motivadoras para que la secuencia se pudiera desarrollar hasta el final sin problema;

- los aprendizajes cognitivos (de qué hablar) y de lenguaje (cómo decirlos) necesarios se harían a lo largo de la secuencia. Desde estos dos puntos de vista, los debates se enriquecerían y mejorarían a lo largo de las sesiones, paralelamente a la calidad artística y técnica de los sketchs. Los alumnos se podían apoyar en sus experiencias prácticas del video y en las críticas de sus compañeros;

- el ámbito sobre el que versaba la actividad de lenguaje era relativamente nuevo para todos (en esa época, pocas familias poseían una cámara de video). Los alumnos estarían en igualdad de condiciones en lo que concierne a una parte del contenido (la técnica de realización sobre la que debía llevar, en parte, la discusión).

La observación de las discusiones nos lleva a moderar bastante el optimismo de las hipótesis que acabamos de enunciar y a evocar los problemas que surgen, bastante frecuentemente, en experiencias similares.

Para motivar el debate, era necesario, evidentemente, que los alumnos, en particular los equipos realizadores de los sketchs, hablaran de una produćción que era suya, que les había interesado porque estaban implicados en ella, porque correspondía a una creación relativamente espontánea, sin coacciones exteriores más que aquellas impuestas al principio (película muda, filmada en el recinto del colegio), sin censura de contenido ni de expresión.

Al leer los resúmenes de las 8 películas (véase anexo), ya se notará que los sketchs eran de calidad desigual. Algunos de ellos eran casi incomprensibles para quien no había tenido previamente acceso al guión. La originalidad del tema, la calidad de la direción, la habilidad en el manejo de la cámara (enfoque, por ejemplo) variaban claramente de un grupo a otro. He aquí lo que constituye aparentemente una situación ideal para entrenarse en la crítica. Pero cuando ésta tiene como objeto, en ciertos casos, despellejar más o menos sistemáticamente al otro, tiene un efecto más bien desmoralizante en el equipo del que se trata. Por otra parte, tiende a inquietar a aquellos que pasarán después por el banquillo; un fenómeno de bloqueo afectivo les impide aprovechar las sugerencias implicadas en estas críticas.

Esta sensible diferencia de calidad se reveló todavía más embarazosa cuando recubría más o menos la separación entre Latino-Moderna y General. La hipótesis según la cual, este último grupo se encontraría más a gusto porque la actividad de la cual se partía era de tipo no verbal, visual, resultó ser falsa ${ }^{2}$. Debido a sus conocimientos en distintos ámbitos (técnicos y artísticos), a sus lecturas, a sus costumbres como telespectadores, a su nivel intelectual o a aportaciones culturales de su medio familiar, los alumnos de Latino-Moderna estaban, al principio, en situación de superioridad a muchos niveles (y no solamente porque sus criterios estéticos correspondían mejor a los de los adultos presentes en la clase). Tal situación no mejoró, evidente- 
mente, las relaciones entre los grupos concurrentes. Se encontrarían tales diferencias en una clase heterogénea, en la que los equipos se formasen de manera homogénea, o en todos aquellos casos en que los alumnos están individualmente en competición (cf. en redacción tradicional, en la lectura en voz alta del maestro de composiciones seleccionadas). Por otra parte, son probablemente raros los contenidos o actividades en las cuales los alumnos estarían verdaderamente en situación de igualdad, a menos que se saliera de las situaciones escolares habituales, lo que puede ocasionar problemas del punto de vista práctico o administrativo y sobrecargar singularmente la operación.

En esta experiencia, la regla del juego era que los profesores no intervinieran de modo alguno en la fase de elaboración de los sketchs. Esta política de no intervención del maestro es igualmente la regla en muchas de las situaciones de producción de textos (en sentido amplio): es raro que se busque previamente una cierta igualdad del nivel de los alumnos en lo que concierne al tema que será el objeto de la redacción (o de la intervención oral), o incluso que se les entrene a ciertas técnicas de creatividad (por ejemplo, en el ámbito de la narración (cf. Bach, 1987)). Nuestra propia concepción didáctica (cf. Pédagogie du texte II, 1988) nos incita a prever, en cada etapa de una secuencia, una fase primordial de elaboración del contenido, que tiende a este igualamiento de la preparación de los alumnos en el ámbito escogido. Si proyectáramos una nueva experiencia análoga, preconizaría pues una preparación «técnica» más importante y una mayor ayuda a los alumnos o equipos que lo necesitaran, en beneficio mismo del debate que sigue.

No ignoramos que tales intervenciones son delicadas, que deben ser discretas para no molestar o vejar a aquellos a quienes van dirigidas. En especial, se corre el gran riesgo de sustituir los criterios (sobre todo estéticos) de los alumnos. ¿Hasta qué punto se les debe influenciar, introducirlos en normas imperantes en el ambiente o en aquellas de los medios más cultivados? En esta investigación, vivimos un incidente que muestra que, en ciertas circunstancias, estas normas pueden llegar a ser muy apremiantes e intervenir como una instancia de censura, volviendo problemática una política motivadora de «liberación de la expresión». En el momento de esta experiencia, y por diversas razones, el «Cycle d'orientation» era el blanco de una campaña de prensa que criticaba algunas de sus prácticas pedagógicas. Poco antes, un artículo había denunciado la tendencia de esta escuela a alentar la violencia y puesto en la picota a una profesora que había propuesto como título de una composición algo de tipo: "El hombre de las gafas azules ha golpeado nuevamente». Del mismo modo, cuando la dirección de la escuela leyó los 8 resúmenes del anexo 1, se alarmó al encontrar en la mitad de ellos, episodios de violencia $\left(n^{\circ} 3\right.$ : asesinato de un niño y ejecución del asesino; $\mathrm{n}^{\circ}$ 5: cómo desembarazarse definitivamente de un inoportuno provocando un accidente; $n^{\circ}$ 6: pelea general entre hinchas al final de un partido; $n^{\circ} 7$ : asesinato en un tren; tres de estos sketchs fueron producidos por equipos de G). Se les reprochó entonces, a posteriori, a los profesores (e indirectamente a los investigadores), haber dejado pasar tales temas, no haber propuesto otros, menos violentos y culturalmente más ricos. Al mismo tiempo, la difusión de un informe de esta experiencia, que podía dar la impresión de garantizar esa pedagogía del dejar hacer y de promover la violencia ( $\sin$ hablar del adulterio, cf. sketch $n^{\circ} 4$ ), era inoportuna.

Una pedagogía de la lengua oral, fundada en una perspectiva de «liberación de la palabra» como elemento de motivación, corre el riesgo de chocar, bajo otras formas, con la intervención más o menos enmascarada de una censura semejante. Y no necesariamente además por parte de la dirección de la escuela; las asociaciones de padres sustituyen a veces la indignación de ciertas familias ante los temas propuestos para la discusión, que pueden cuestionar valores o consignas familiares (Ejemplo de 
tema argumentativo propuesto por los alumnos: la hora de vuelta a casa después de una superfiesta). A menudo, es más económico y menos peligroso para el maestro tratar temas más clásicos y potencialmente menos conflictivos, porque no afectan directamente a nadie.

Por otra parte, el problema no es sencillo. Es probable que una cierta distancia respecto al tema tratado sea favorable para el aprendizaje a nivel de lenguaje. El objeto sobre el que se lleva a cabo la actividad de lenguaje debe ser interesante sin acaparar completamente a los alumnos. En nuestra experiencia, en efecto, los alumnos se cansaron bastante rápidamente de los debates comunes, el placer de realizar un sketch video era, según ellos, ampliamente suficiente» (Boget y col., p. 4). A menudo, se encuentra esta dificultad cuando se busca motivar la producción de un texto por los alumnos mediante actividades diversas previas: visita a una empresa, entrevista de un especialista o de un aprendiz (información profesional), lectura de textos polémicos, etc. Para el maestro de francés esta preparación es una actividad pretexto ( o pretexto!), mientras que para los niños o los adolescentes se convierte en central y principal, lo que confiere un carácter más o menos «incordiante», a las actividades de lenguaje que les siguen. Del mismo modo, cuando los alumnos han tenido la posibilidad, en una fase previa, de discutir oral e informalmente de un tema que les apasiona, ya no tienen ganas de empezar nuevamente la operación formalmente y por escrito. Cuando en una etapa intermedia intentamos mejorar el manejo de ciertas unidades de lenguaje, es probablemente imprudente proponer a alumnos textos sobre un tema que les toca demasiado de cerca. Lo experimentamos cuando propusimos a una clase de $9^{\circ}$ que marcaran los organizadores textuales en artículos polémicos sobre el tema: a favor o en contra del carné de conducir una motocicleta a los 16 años en lugar de a los 14 . Ante la amenaza que planeaba sobre su «amotillo» ${ }^{3}$ favorito los aspectos formales del texto se volvían absolutamente secundarios para los adolescentes.

Otra explicación de la lasitud de los alumnos es el hecho de que la secuencia se prolongara durante varios meses. La experiencia muestra que a menudo resulta necesario un cambio más rápido de actividades para mantener la motivación de los alumnos, en particular de los más flojos. Es, sobre todo, el caso de los alumnos que conceden poca importancia al trabajo que se les propone, o cuando ven que apenas progresan.

Vamos a interesarnos ahora a este aspecto esencial de una secuencia didáctica: su eficacia en relación a los objetivos fijados.

\section{EL APRENDIZAJE DE LA DISCUSION SIN INTERVENCION DIDACTICA}

\section{La toma de palabra}

El dispositivo, en la mente de sus promotores, debía contribuir a favorecer la participación de los alumnos que normalmente y a menudo no se expresan. Ciertos aspectos se consideraban favorables para este objetivo:

- hablar de su producción debía ser para los alumnos una motivación para expresarse más;

- adquirir la experiencia práctica del rodaje debía contribuir a dar a cada uno un buen dominio del tema y la confianza necesaria para hablar del mismo;

- no sufrir una evaluación de su intervención por parte del maestro (que sólo regulaba la situación) debía hacer perder al alumno sus reticencias para expresarse. 
Los profesores partían de la hipótesis de que, por esta razón, la palabra se repartiría mejor tanto entre los alumnos como entre las clases. Suposición que se ve desmentida en nuestros cálculos (figura 3). El número medio de intervenciones por alumno fue alrededor de 13 para la totalidad de las 8 sesiones, pero, de hecho, variaba de 0 (11 alumnos de 41 ) a 80 (1 alumno); la distribución asimétrica se concentraba entre 0 y 16. Para un número de interlocutores potenciales sensiblemente igual, las tomas de palabra fueron una vez y media más frecuentes en los LM que en los $G$ (en total, 304 versus 216 ). La proporción de alumnos sistemáticamente «mudos» fue la misma en ambos grupos, se observaba pues esencialmente una diferencia en las frecuencias individuales de intervenciones entre ambas clases.

FIGURA 3

Frecuencia de las intervenciones

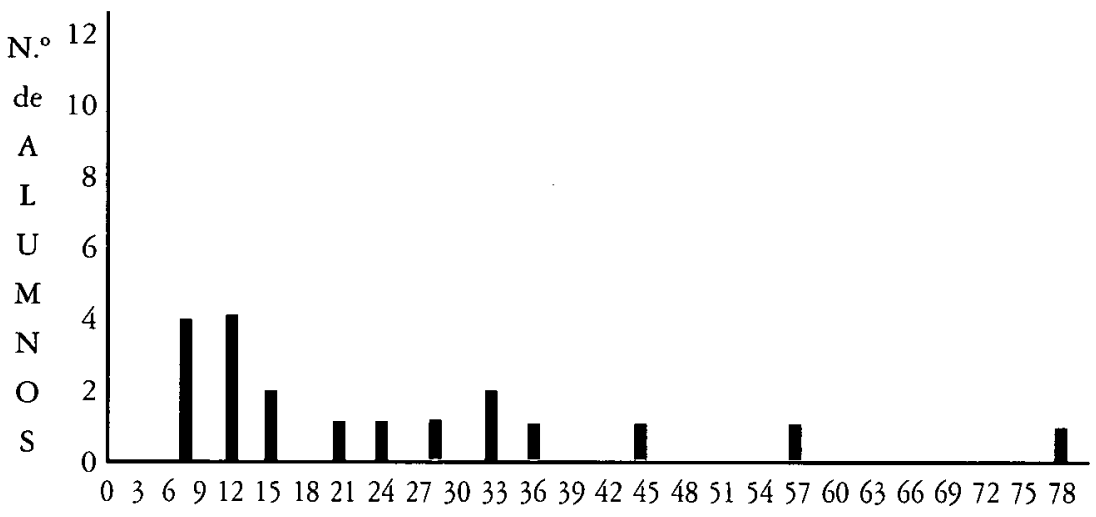

Número de intervenciones por alumno del total de las 8 sesiones

$\mathrm{La}$ interpretación es sólo aparentemente sencilla. Los LM tienen probablemente más cosas que decir, menos obstáculos de lenguaje para decirlo (al menos en las formas relativamente académicas propias del ámbito escolar) y más ganas de decirlo. Se encuentran características intelectuales y lingüísticas que correlacionan directamente con la selección escolar realizada al principio del «Cycle d'orientation». Ésta tiende a clasificar (con varios errores) a los alumnos en $\mathrm{G}$ en función de sus insuficiencias o actuaciones inferioresrespecto a los criterios que acabamos de mencionar. Sin embargo, esta explicación de las diferencias entre LM y G es insuficiente: veremos que las representaciones de las «reglas del juego" no eran las mismas para ambos grupos y que es necesario un enfoque sociolingüístico para matizar la explicación.

«Para tomar la palabra, se tiene que tener (jen general!) algo para decir y sentirse capacitado para decirlo». He aquí una primera regla implícita que funcionaba de forma distinta según el grupo. Durante las primeras presentaciones de sketchs realizados por equipos LM, las intervenciones de la clase $G$ provenían, casi en su totalidad, de alumnos que ya habían filmado su sketch antes de la discusión o que estaban implicados como actores. Contrariamente a esto, sus compañeros de LM tomaban la palabra hubieran o no participado previamente en un rodaje. Todo ocurrió pues, como si los alumnos de $G$ necesitaran la práctica para sentirse implicados y aptos para criticar la película del otro grupo, mientras que los LM se sentían capacitados para intervenir y capaces de criticar sin haberse beneficiado de esta experiencia.

Aparte de la situación particular aquí descrita, esta constatación me parece importante a nivel didáctico. La fase de elaboración del contenido debería intentar implicar de la mejor manera posible a todos los alumnos - y en especial a los más flo- 
jos - en la actividad objeto de la producción oral, tanto a nivel cognitivo (conocimientos y savoir-faire) como afectivo. ¡Ideal que preconizan todos los métodos activos y que nos cuesta tanto realizar!

En lo que respecta a la toma de palabra, el dispositivo didáctico produjo pocas modificaciones desde el punto de vista de las capacidades y actitudes del principio. Pudimos verificarlo a nivel individual. En efecto, habíamos pedido a los profesores, antes del comienzo de la experiencia, que clasificaran a sus alumnos en tres categorías según su participación en las clases de francés: intervenciones frecuentes, ocasionales o raras. Los hábitos de los alumnos en este ámbito no se modificaron apenas: durante las 8 sesiones de nuestra secuencia, las medias de tomas de palabra fueron respectivamente de 39, 8 y 3 en los tres grupos definidos previamente por los maestros.

Esto se explica (¡a posteriori!) bastante fácilmente. En primer lugar, las condiciones suscepribles de favorecer una mayor participación de los alumnos poco elocuentes en clase se encontraban probablemente contrabalanceadas por diversos inconvenientes. El número de alumnos reunidos para las sesiones de discusión era con mucho demasiado importante para no frenar a un alumno tímido. Incluso si tenía alguna contribución para llevar a la discusión, podía temer la crítica de alumnos que no pertenecían a su ambiente habitual. Sólo contamos las intervenciones «oficiales», identificables; el cuadro sería probablemente un poco distinto si hubiéramos podido identificar a los autores de varias conversaciones entre sí audibles en nuestras grabaciones. Sea lo que fuere, es siempre más difícil tomar la palabra en una gran asamblea; parecía preferible empezar el aprendizaje en un grupo más restringido (por ejemplo, intercambio entre dos equipos), en el que los alumnos se sentirían más cómodos.

Después, el momento ideal para expresarse con conocimiento de causa era aquel en el que el alumno podía, como miembro de un grupo, defender su propia producción. Pero esta defensa era a menudo tomada por un «líder» del grupo, de este modo, el alumno poco activo ya no se veía obligado a hablar. Estos problemas de liderazgo ya existían probablemente con anterioridad, durante la preparación del sketch, sin que conociéramos la correlación entre toma de palabra y actividad de realización de la película.

Por último, la no intervención del maestro, que debía suprimir en ciertos alumnos, el temor a ser interrumpidos o corregidos, impedía solicitar la participación de los elementos poco locuaces, que podían parapetarse tras compañeros más charlatanes. Por otra parte, se sabe que la táctica de varios alumnos, que otorgan sólo un tiempo moderado a las actividades escolares, es, lo más a menudo posible, trabajar lo menos posible en las clases que se lo permiten. En un gran grupo son todavía menos «visibles» que de costumbre, por no hablar del hecho de que el tiempo de palabra medio posible por alumno es aún más corto que en la clase ordinaria (alrededor de un minuto: $40 \mathrm{mn} / 40$ alumnos). De nuevo, parece cierto que el aprendizaje de la discusión o del debate se haría en mejores condiciones prácticas y socio-afectivas de participación, si tuviera lugar en un grupo relativamente restringido, en el cual la no intervención es no sólo descubierta, sino a menudo interpretada como manifestación de una cierta actitud (de indiferencia o de hostilidad). Es cierto que así se aumentaría la coacción escolar sobre el individuo; ¿Sería esto deseable?

\section{La competencia argumentativa}

La capacidad de los alumnos para argumentar, ¿evolucionó, globalmente, del principio al final de la secuencia? Para responder a esta pregunta, se trata, en primer lugar, de definir lo que nosotros entendemos por competencia argumentativa. No es 


\section{1}

éste el lugar para desarrollar detenidamente este tema (cf. Commission Pédagogie du texte, 1988).

En el marco de esta experiencia, nos limitaremos a un aspecto de la competencia argumentativa exigida por la situación de interacción: la capacidad para formular y justificar de manera adecuada una evaluación. Para operacionalizar esta definición, hemos recurrido a un modelo propuesto por Meux (1963), que nos permitió aislar en nuestras grabaciones todos los fragmentos correspondientes a lo que este autor llama episodios evaluativos. Éstos se caracterizan por cuatro elementos:

1. El objeto de evaluación (Oe), que es una constatación, una expresión, un acontecimiento, una acción o un estado de cosas para evaluar.

2. La apreciación (A) de este objeto en términos tales que bueno, bien, falso, deseable, etc.

3. La justificación (J) mediante la cual se fundamenta o apoya la apreciación.

Figura 4

Modelo de evaluación según el esquema de Meux (1963)

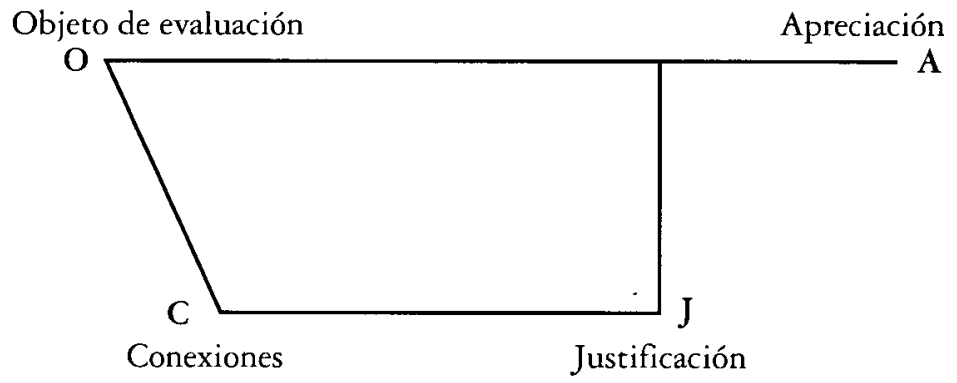

4. Conexiones (connecting facts, $\mathrm{C}$ ) relativos al objeto, que establecen una relación (R) entre éste y la justificación y que, por ello, legitiman el recurso a esta justificación en la evaluación del objeto (cf. fig.4).

En un primer momento, para la evaluación oral, más somera que una argumentación escrita, únicamente los tres primeros elementos demostraron poder aplicarse a nuestro corpus. Para apreciar la evolución de las evaluaciones, introdujimos las siguientes modalidades descriptivas o cualitativas en el seno de estas tres dimensiones de observación:

1. Objetos de evaluación global y/o impreciso versus explícito o preciso: "Yo encuentro que estaba bastante bien ${ }^{4}$.

frente a

«Encuentro que los disfraces, eran verdaderamente perfectos».

2. Apreciaciones implícitas o indirectas (constataciones, demostraciones, sugerencias, preguntas, exclamaciones o suspensiones de la frase) frente a explícitas (juicios formulados):

"En la pelicula, como binchas, ¿queriais mostrar que érais realmente chiquillos, o qué??; sobreentendido: vuestra representación de verdaderos hinchas (adultos) fue más bien un fracaso (sketch $\mathrm{n}^{\circ} 6$ ).

frente a

«Su sketch, hubiera tenido que ser con música; sin música, no tiene ningún sentido; es tonto» (sketch $\mathrm{n}^{\circ} 1$ ).

3. Justificaciones (categorización modificada en relación a la de Meux):

- ausentes: «Las tomas de vista no estaban mal hechas». 
- subjetivas, relacionadas con factores personales: « $¡$ No creo que yo lo hubiera encontrado (comprendido) solo!».

- por referencia a un criterio: «Lo que interpretaban era bastante gracioso, era la exageración de los movimientos, esto daba un pequeño algo?»?

En este último caso, distinguimos diversas subcategorías en función de los criterios o aspectos de la película invocados: aspectos técnicos del video; dirección, realización, decorados, trajes; interpretación de los actores; lógica de la historia: precisión, coherencia, exhaustividad, carácter de los personajes; organización de la historia: (super)estructura, desarrollo, transiciones, puestas en evidencia; originalidad; adecuación entre el medio y el guión (cf. supra, la observación a propósito del sketch $\left.\mathbf{n}^{\circ} 1\right)$.

Como se puede constatar, nos hemos fijado especialmente en la justificación. Meux estima, en efecto, que justamente de ella depende la calidad o la corrección de la evaluación. Por otra parte, sabíamos por experiencia que en el texto argumentativo es el desarrollo de la argumentación (en nuestro caso, la motivación de la apreciación hecha de la película o de uno de sus aspectos) lo que es problemático al principio del aprendizaje.

A posteriori, nos damos cuenta que nuestra clasificación es arbitraria y que las subcategorias de justificaciones hubieran podido ser definidas también a propósito del objeto de evaluación (Oe). Además, los tres elementos retenidos están más o menos relacionados y la pertinencia de las justificaciones sólo puede estimarse si se tiene en cuenta su relación $(\mathrm{R})$ con el resto de la evaluación. De este modo, adoptamos otra clasificación, más global, de los episodios evaluativos, repartiéndolos en «correctos o satisfactorios» $(\mathrm{E}+)$ frente a «incorrectos o insatisfactorios» (E-). Una evaluación, para ser juzgada como correcta, debe a la vez explicitar el objeto $\left(\mathrm{O}_{+}\right)$a partir del cual se lleva a cabo la apreciación, y esta apreciación misma $(A+)$, proporcionar una justificación precisa y pertinente $\left(\mathrm{J}_{+}\right)$, diferente a la expresión de una simple impresión personal y presentar una relación lógica y adecuada entre el objeto citado y la justificación dada $\left(\mathrm{R}_{+}\right)$.

\section{Ejemplos:}

«Encuentro incluso que había demasiados $\left(\mathrm{A}_{+}\right)$[cortes $\left(\mathrm{O}_{+}\right)$].

Cuando hacemos cosas así, es para indicar que la escena que sigue ocurre después de algunos días, algunos instantes» $(\mathrm{J}+, \mathrm{R}+) .=\mathrm{E}+$.

frente a

"Encuentro de nuevo que esta secuencia $(\mathrm{Oe}+)$ es demasiado larga $(\mathrm{A}+)$, porque la veíamos caer, pero no se veía bien el rodillo de cocina». $(\mathrm{J}+$, pero $\mathrm{R}$ - la justificación no se hace a propósito del objeto evaluado) $=>\mathrm{E}-3^{6}$.

Apunto ya desde ahora que, desde el punto de vista didáctico, a menudo es importante disponer de un «modelo» que estructure y precise el objeto de enseñanza. Este modelo es aún más útil si puede ser tansmitido bajo una forma más o menos adaptada a los alumnos. Constituye una preciosa referencia para una evaluación formativa, sobre todo en su forma más integrada: la autoevaluación. Este modelo se traduce para los alumnos bajo la forma de una «parrilla de control», construída, a menudo, con ellos. Sé que ciertos profesores se oponen a esta «modelización», temiendo que mate una cierta espontaneidad y creatividad de los alumnos y que acabe en un estereotipia de los enunciados. En la práctica (cf. Commission Pédagogie du texte, 1988), este temor se revela exagerado: los alumnos saben jugar con el modelo, sobre todo los mejores elementos de la clase, que se dan implícitamente una consigna de originalidad (cf. infra). Para los otros, la esquematización se revela útil en un primer momento y probablemente constituye un punto de paso obligado hacia más libertad. Además, prefiero correr este riesgo de estereotipia que encontrar- 
me en una situación molesta, desgraciadamente muy corriente (en especial en la lengua oral): aquella en la que objetivos y criterios permanecen implícitos, vagos, escondidos, indiscutibles porque son controlados por un solo actor: el maestro. Uno de los puntos débiles de la secuencia didáctica de la cual informamos fue precisamente la de no proporcionar a los alumnos el esquema simplificado de Meux. ¿Cuándo hubiera sido más eficaz hacerlo? Volveremos a esta pregunta cuando hagamos, en la parte final de discusión y conclusión, una crítica global de la operación.

Si volvemos nuevamente a los criterios definidos anteriormente $(A+, J+, R+$, $\mathrm{E}+$ ), comprobaremos que las competencias que evaluamos mediante los mismos son complejas, tanto a nivel cognitivo como de lenguaje. Para satisfacer las exigencias así definidas, el alumno debe ser capaz: de discernir y de aislar en la película que ha visto, diversos aspectos (técnicos, lógicos, artísticos); de encontrar la formulación adecuada identificando lingüísticamente el objeto y la calificación que se le da; de elaborar una justificación pertinente; y de expresar su vínculo lógico con el objeto y su apreciación (sobre todo, correcta utilización de conectores y anáforas).

¿Evolucionaron dichas capacidades durante la secuencia didáctica? ¿En este campo, no sería suficiente un aprendizaje espontáneo e incidental ? ¿en qué aspecto la intervención se revelaría como más necesaria? Para juzgar los progresos, hemos dividido las 8 sesiones en dos etapas: lecciones 1 a 4 y 5 a 8 y comparado las producciones desde el punto de vista de los criterios definidos anteriormente.

En la mayor parte de los casos, los alumnos identifican con una cierta precisión el objeto $(O e)$ que están evaluando. Las observaciones globales, imprecisas son bastante minoritarias y tienden a disminuir de la primera a la segunda fase (de $19 \%$ a $6 \%$ ). La discusión tiende a llevar la regulación necesaria al aprendizaje: los especialistas de la observación vaga son corregidos por sus compañeros, que les piden precisiones, a veces en un tono bastante vivo de reproche. Cuando se es el autor de un sketch, no se puede dejar pasar una crítica vaga. Ésta es siempre más molesta que un ataque concreto, al cual es más fácil responder. En este punto, la interacción entre alumnos, tal y como es prevista por el dispositivo didáctico, es pues relativamente eficaz en sí misma. Pero es necesario observar que este tipo de aprendizaje (precisión a propósito del objeto) se lleva a cabo en un ámbito poco problemático al principio, para una gran mayoría de las dos clases.

¿Se observará, correlativamente, una mejora de la precisión en la formulación de las apreciaciones (A)? Ocurre al revés: la proporción de apreciaciones explícitas tiende a disminuir en la segunda fase de la experiencia (del $49 \%$ al 39\%), y ser ésto es así en ambos grupos. Si se analiza, esta evolución está lejos de ser negativa: todo ocurre como si los alumnos prestaran cada vez más atención a evitar un ataque demasiado directo. Pero su manera de renunciar a una crítica demasiado explícita varía: mientras que los $\mathrm{G}$ recurren más a la simple constatación (..., solamente esta escena, «era siempre lo mismo, casi»), los alumnos de la clase LM emplean formas más sutiles de apreciaciones implícitas, sobre todo la sugerencia, utilizando de esta manera lo que han aprendido y discutido en el curso de la experiencia. Se ve pues que se inicia un aprendizaje de la discusión y de la crítica, que hace aparecer una dimensión socioafectiva o sociolingüística de la interacción de lenguaje en la cual el profesor no piensa inmediatamente. Este aspecto del discurso en situación ha sido bien descrito por Roulet (1991): para que la constatación no se rompa con su interlocutor, se tiene que evitar «hacerle perder la cara». En los contactos de la vida cotidiana, recurrimos para ello a diversas estrategias: dudas, preguntas previas, observaciones indirectas, etc. El debate ha permitido a ciertos alumnos iniciar una toma de conciencia de dichos fenómenos, que, por otra parte, no fueron jamás explicitados en el curso de las 8 sesiones. Esto no significa que dicha explicación hubiera sido inútil. En una fase de análisis reflexivo (metacomunicativo) llevado a cabo por los alumnos a propósito de 
su propio funcionamiento, dicha toma de conciencia hubiera constituido, seguramente, un refuerzo eficaz, que favorce una transferencia a otras situaciones.

Un análisis detallado de los tipos de justificaciones $(\mathrm{J})$ no muestra una diferencia importante entre ambas fases de la experiencia. Sobre todo, no es posible poner de manifiesto un aumento de los argumentos técnicos (manejo del video, adecuación entre el medio y el guión) que se hubiera podido esperar, por el hecho de que cada vez más alumnos estaban activamente implicados en la experiencia y habían hecho su aprendizaje prácrico de la filmación.

Extrajimos las siguientes conclusiones, probablemente pertinentes para otras secuencias didácticas de lenguaje (orales o escritas). Ya lo hemos dicho, es evidentemente importante que los alumnos hablen de cosas que conocen, de las que tengan una buena experiencia práctica y una buena comprensión intelectual, que tengan ganas de expresar o comunicar al otro. Si carecen de esta aprehensión del objeto de discurso es indispensable ofrecerles la posibilidad de adquirir previamente los conocimientos, savoir-faire, representaciones y motivaciones necesarios. Sin embargo, nuestra experiencia con el video muestra que esta elaboración no puede ser únicamente prácrica o puramente cognitiva (imágenes mentales, conceptos abstractos). Es tanto más indispensable preparar a los alumnos para verbalizar y textualizar: para dar nombres a los objetos que manejan en situación (y, que por ello, no tienen necesidad, a menudo, de denominación explícita); para organizar lo que tienen que decir en un discurso (incluso breve) mínimamente coherente, estructurado (conectores, pausas, puestas en evidencia, ...) y modalizado ( Según mi opinión, probablemente, es evidente que ...»). Este aprendizaje no se bace espontáneamente; se impone una intervención didáctica específica, es decir una elaboración de la forma.. A menudo, ésta se plantea estrechamente unida a la elaboración del contenido. Sin embargo, insistimos en que algunos aprendizajes incidentales no son suficientes para ello; por ejemplo, con motivo del manejo de los aparatos: en ese momento, los alumnos tienen otras preocupaciones, prácticas, y la formulación lingüística no siempre es necesaria. Esta elaboración de la forma debe ser objeto de ejercicios explícitos. Si éste no es el caso, sólo lo conseguirán aquellos alumnos que ya tienen las competencias de lenguaje necesarias.

Encontraremos el mismo problema didáctico cuando consideremos la calidad global de las evaluaciones. Una sensible progresión, pero poco espectacular, se observa entre ambas fases. En la primera, hemos contado que el 55\% de evaluaciones explicitan su objeto y su apreciación y proporcionan una justificación pertinente; en la segunda, esta proporción se eleva al $73 \%$. Un progreso del $18 \%$ parece relativamente flojo cuando consideramos la importancia del dispositivo didáctico y el número de horas consagradas a la secuencia didáctica ${ }^{7}$.

En término medio, los resultados de los $\mathrm{G}$ permanecen inferiores a los de los LM (para las 8 sesiones: el 68\% de evaluaciones correctas en LM y el $58 \%$ en G). Sin embargo, nuestra evaluación de la calidad global de las evaluaciones es seguramente demasiado pesimista. En efecto, la clasificación adoptada (cf. supra) descalifica ciertas intervenciones evaluativas a causa de una apreciación no explicitada $(\mathrm{A}-=>\mathrm{E}-$ ), mientras que, a nivel socio-afectivo, esta forma de crítica es a menudo perfectamente adecuada, incluso más adecuada que una evaluación explícita.

\section{Cualidades y corrección del discurso desde el punto de vista de la lengua}

Abordaré este aspecto muy brevemente, y no sin motivo. Nos falta para ello, un modelo de referencia que describa las características morfosintácticas de un discurso oral adecuado al marco escogido. Las normas que tenemos generalmente en 
mente son las de la lengua escrita. Nosotros mismos no las observamos en absoluto en un debate, incluso relativamente formal, como lo demostraría una grabación de nuestras discusiones habituales en un medio profesional.

Por lo que respecta a nuestra secuencia didáctica, se puede afirmar sencillamente que las posibles incorrecciones en este ámbito no han chocado a los alumnos (únicos jueces válidos en el espacio social implicado: relaciones entre pares) y que raramente han sido, como tales, obstáculos a la comunicación. En un discurso poligestionado, poco formalizado, la interacción permite a los interlocutores pedir precisiones o complementos necesarios a la mutua comprensión, hacer explicitar lo implícito, etc. Además, el objeto de la discusión (el video sketch) era conocido por todos. Es cierto que un esfuerzo en la precisión del vocabulario hubiera sido deseable para varios alumnos, pero esto nos lleva a los problemas tratados anteriormente que muestran, además, la necesidad de enlazar la elaboración del contenido (producción y análisis de las películas) con la de la forma (medios de lenguaje para hablar de los mismos).

A nivel de la sintaxis, la transcripción de la grabación pone en evidencia numerosas frases no terminadas, rupturas de construcciones y otros anacolutos, conectores mal utilizados (cf. el porque, en unos de los ejemplos anteriores). Sin embargo, nada o apenas nada que haya causado problema en el mismo momento, en el marco considerado. ¿Sería necesario aumentar, en tal caso, el carácter formal de la situación ${ }^{8}$ simulando un marco o lugar social diferente? En todo caso, se trataría de explicitarlo (intervención en un jurado de concurso, que incluyera adultos, por ejemplo). La apuesta sería, sin ninguna duda, difícil de mantener, habida cuenta del carácter afectivo y de lo que está en juego a nivel social (roles y estatus de cada uno en la clase o en relación a la otra clase). La experiencia muestra que dicha simulación es más fácil con clases de tipo Latino que con Generales, ya que estas últimas tienen una relación más inmediata con la situación hit et nunc y tienen más dificultad a «hacer como si».

\section{¿INTERCAMBIO O CONFRONTACION? LOS PROBLEMAS SOCIOLINGÜISTICOS DE LA ARGUMENTACION ORAL}

Como hemos visto, los promotores de la experiencia partían de una hipótesis relativamente optimista sobre las virtudes de un intercambio entre dos clases de distinto estatus escolar: estas diferencias debían enriquecer la discusión y se suponía que ésta debía llevar a un cierto acercamiento y a una cierta colaboración entre ambos grupos. La experiencia mostró que se corrían grandes riesgos de llegar a resultados totalmente opuestos, convirtiéndose el intercambio en confrontación. Vamos a mostrar cómo.

Tomemos primero la precaución de decir que este fenómeno no está relacionado con el dispositivo adoptado, de juntar dos grupos diferentes. Mecanismos del mismo tipo podrían tener lugar en el interior de una clase, incluso presuntamente homogénea, en la cual la posición escolar y social de los alumnos es raramente idéntica. Según lo que haga el maestro, éste puede desarrollar rivalidades y reforzar las diferencias allí donde quería promover la colaboración y la disminución de las desigualdades. Se llega a dicho resultado cuando se ignora que al principio todos los alumnos no adoptan, implícitamente, las mismas «reglas del juego» en los juegos sociales a los que se les invita en ciertos ejercicios o en ciertas experiencias.

En este capítulo, hemos estructurado nuestros análisis de contenido de las discusiones en cuatro aspectos: rivalidad, divergencias de puntos de vista, confrontación y agresividad, colaboración e integración. 
Rivalidad entre clases

Esta rivalidad se manifestó en una crisis: en la tercera sesión la mayoría de los alumnos de ambas clases rechazaron hacer uso de la palabra, a pesar de las órdenes terminantes de los profesores que amenazaban con interrumpir la experiencia y volver a otros ejercicios más tradicionales. ¿Qué ocurrió? Durante la primera sesión, cuando se presentaba un sketch de un equipo de LM, los $\mathrm{G}$ se dieron cuenta que sus compañeros no actuaban honradamente: se reservaban la crítica de la producción de los alumnos "de su campo»: "Encuentro que los de la otra clase (LM) deberían bablar más de su sketch (el del equipo LM), porque no bay nadie que diga nada» (alumno de $\mathrm{G}$ ). De manera concertada o no, pagaron con la misma moneda a la clase contraria en la segunda sesión. De ahí, el mutismo general después de la tercera presentación. Esta rivalidad, que lleva a cada clase a intentar defender su sketch y a atacar el del otro, aparece claramente, a nivel de lenguaje, en la utilización de pronombres o de adjetivos deícticos: «nosotros, lo bacemos todo ... ", "nnestro guión era mucho más pequeño ...»; "nosotros, es una bistoria en donde bay cambios de lugar (...), mientras que vosotros, permanecéis siempre en el mismo sitio ...». Es necesario señalar que mediante su silencio, los alumnos traducen, en un primer momento, la negación de dicha competición.

Este aspecto de la experiencia les abrumó hasta el final, como nos revelaron durante una última discusión, destinada a verificar la manera en que los alumnos habían vivido dicha rivalidad. Sin embargo, como la experiencia se prosiguió, de la quinta a la octava sesión constatamos una diferencia de táctica entre los LM y los G. Los primeros, habiéndose aficionado al juego intelectual de la evaluación, dirigieron críticas bastante numerosas, incluso más numerosas según nuestros cálculos, a sus propios equipos que las formuladas por los $\mathrm{G}$ con respeto a las producciones de LM. En cambio, los $\mathrm{G}$ continuaron la táctica que consistía en evitar dirigir críticas a sus propios equipos. Se trata en este caso de comportamientos específicos de estos dos grupos. Pero, tal vez, también se pueda ver la consecuencia de normas o costumbres relacionadas con los medios socio-culturales de los cuales provenían estos alumnos, así como un cierto estilo intelectual o cognitivo correspondiente a su nivel escolar. Parece como si los alumnos de $\mathrm{G}$ se hubieran puesto de acuerdo para no atacar demasiado a sus equipos, especie de táctica de defensa en esta confrontación en la cual sentían, quizás, que no luchaban, del todo, en igualdad de condiciones. En los LM, tal vez más individualistas y autónomos, sus duras críticas no parecían poner en peligro el espíritu de clase ni las relaciones sociales de costumbre. Las reglas del juego no parecen haber sido las mismas en ambas clases. La funciones en el uso de la palabra, o más ampliamente del lenguaje, tampoco. En LM, la intervención en el debate constituía, en apariencia para algunos, la oportunidad de distinguirse, de hacerse resaltar, de diferenciarse de los demás. En G, el lenguaje (y sobre todo las consignas dadas probablemente por ciertos líderes fuera de las sesiones) parece haber tenido como finalidad conservar la cohesión del grupo, consolidar los lazos entre sus miembros". Pero no es el único aspecto en el que constatamos diferencias.

\section{Diferencias de puntos de vista entre LM y G: los criterios de evaluación}

Hemos puesto de manifiesto las divergencias relativas sobre todo a la concepción de los sketchs y a ciertos criterios de referencia en cuanto al valor o al interés de tales producciones. A partir de las observaciones de los LM, y simplificando mucho $^{10}$, se podría decir que para muchos de estos alumnos un buen sketch televisado debía tener las características siguientes: 
- transmitir un "mensaje», mostrar o demostrar algo: « ¿Querías mostrar algo con vuestra película?" (pregunta de un alumno de LM al equipo de G); uno de los sketchs, con función catártica para la clase de $8^{\circ} \mathrm{LM}$, representaba la exclusión de uno de los alumnos (negro) del juego de cartas = del grupo;

- presentar una buena coherencia lógica y psicológica (guión y personajes) para el espectador: ¿se puede tomar en broma un tema, como por ejemplo, la pena de muerte? ¿es normal que los hinchas durante un partido se comporten como chiquillos (reproches dirigidos a dos películas de $\mathrm{G}$ )?

- manifestar una cierta originalidad: «bemos intentado no bacerlo como los demás».

Desde el punto de vista de estos criterios, la mayor parte de los sketchs de $G$ eran claramente criticables. Sin embargo, no es seguro que los interesados hayan comprendido $o$ aceptado las críticas basadas en criterios que no eran necesariamente los suyos. Si nos referimos a sus producciones y a su argumentación, buscaban sobre todo:

- contar una historia, el aspecto narrativo prevaleció claramente en sus sketchs (tres de los cuales de tipo policiaco);

- divertir(se): «No bemos becho una película para bacerlo bien, o eso, bemos becho una pelicula para reir»;

- conseguir una producción estándar antes que hacer gala de originalidad; así por ejemplo, respondiendo a un alumno que reprochaba la falta de originalidad de una película, y tomando nuevamente el tema de un sketch anterior, Denis $(\mathrm{G})$ afirma: «Es mejor hacerlo dos veces, pero hacerlo bueno».

Se comprende entonces la irritación de los G ante las críticas de los LM, que se referían implícitamente a criterios y a valores que no compartían. Al no haber permitido la discusión poner en evidencia el origen de estas divergencias de evaluación, la experiencia no pudo conseguir de manera satisfactoria uno de los objetivos fijados: que los alumnos aprendieran "a lo largo de los encuentros, a aceptar un punto de vista diferente al suyo, especialmente al verse el grupo-clase confrontado con un grupo exterior» (objetivo $\mathrm{n}^{\circ} 2$ ). En casos de este tipo, el problema es también difícil para el profesor que no puede ocultar su preferencia por ciertos criterios y valores en relación a otros. No siempre se da cuenta de que ciertos valores tomados como referencias por los alumnos son los de su familia y los de su medio socio-cultural.

Se encuentra el mismo problema en otras clases de francés (y en otras áreas), pero el ejercicio de argumentación oral favorece una confrontación más directa y a la vez una valorización o desvalorización más inmediata de las posiciones o de los argumentos exhibidos. Tanto más que, en este caso, comportamientos no verbales (tono, mímica, por ejemplo) pueden reforzar inconscientemente las evaluaciones emitidas por el profesor.

\section{Confrontación entre clases, crítica y agresividad}

Digamos enseguida que esta agresividad no tomó nunca un sesgo dramático y que tampoco tiene necesariamente un aspecto negativo. Era relativamente previsible que apareciera una cierta agresividad, teniendo en cuenta el objeto de la actividad de lenguaje (evaluación crítica argumentada) y la dimensión del grupo. Los ataques directos fueron excepcionales: las críticas tomaron más bien la forma de observaciones irónicas o de preguntas insistentes que expresaban la incomprensión ante la producción vista. Por otra parte, no todos los alumnos comprendieron o admitieron de la misma manera el juego de la crítica. Un alumno (de G) percibe las críticas o incomprensiones expresadas como el efecto de una actitud, atribuyéndole una causa socio-afectiva (idea preconcebida), mientras que otros alumnos, sobre todo de LM, 
ven sencillamente la reacción normal a errores técnicos: mala dirección, inadecuación del guión a las posibilidades del rodaje.

De $(\mathrm{G})$ : « Me gustaría decir algo sobre todas las películas que hemos becho. Se diría que todos no tienen ganas de comprender mucho. Lo be observado también en mí. Cuando vemos estas peliculas, se diría que no tenemos ganas de comprender. ;Incluso cuando bay chismes que son vistosos!»

$\mathrm{Da}(\mathrm{LM}):$ ¿De quién es la culpa?"

De (G): «Pero esto, lo digo para todos. Desde todos los chismes que bemos becho desde el principio del año, dos, tres, bueno, tal vez no tenemos ...., pero bay algunos ... j se diría que lo bacemos adrede!»

$\mathrm{Pi}(\mathrm{G})$ : «La pelicula que bemos visto, no es tanto nuestra culpa, es más bien la culpa de los que ban becho la película, porque es bastante incomprensible. Mientras que a veces, somos nosotros los que no queremos comprender».

$\operatorname{De}(\mathrm{G})$ : "; Cuando vemos peliculas en la tele, más complicadas que éstas, pues, comprendemos!»

$\mathrm{Da}(\mathrm{LM})$ : «El video, no es lo mismo que la tele; se pueden bacer trucajes en la tele que no se pueden hacer en el video. Pueden permitirse comprar decorados, mientras que nosotros no tenemos decorados. Para esto, se tiene que adaptar el guión a las posibilidades de rodaje».

$\mathrm{Ma}(\mathrm{G})$ : «La televisión, es el video!»

Diría de buen grado que los LM conciben más fácilmente la crítica como una especie de juego intelectual, mientras que ciertos $G$ (los que se expresaron) sienten más los aspectos socio-afectivos. Se encontrarían tales diferencias en la manera de enfocar la discusión en otras situaciones, más corrientes que la que describimos. No se excluye que el diálogo profesores - investigadores se vea a veces perturbado - sin que esto se vea necesariamente - por diferencias sobre las reglas a respetar en un debate (no autorizarse a intervenir más que si se dispone de una experiencia directa del tema, evitar las críticas directas: jreglas observadas más frecuentemente por los primeros que por los segundos!).

El tamaño del grupo y la agresividad en el ambiente entre las clases impidieron que ciertos alumnos intervenieran o expresaran lo que pensaban de los sketchs, como lo demuestra, por ejemplo, esta observación hecha durante la discusión final (balance de la experiencia con los alunmos):

Lo (G): «Si vuestra clase sólo nos enseñara una película a nosotros, creo que seríamos nosotros los que os criticariamos más, porque en nuestra clase, nos sentimos más cómodos que abora. Les conocemos, pero no conocemos su ambiente, entonces, estamos un poco...».

\section{Colaboración e integración}

La observación de la discusión ha demostrado igualmente que los alumnos de G daban importancia a un principio de solidaridad, de compartir y de integración, a los que los LM eran poco sensibles. Así por ejemplo, los primeros reprochaban a los segundos no haber constituido equipos mixtos chicos - chicas.

De $(\mathrm{G}):(. .$.$) «Encuentro que no es correcto cómo babéis becho vuestros grupos. (...) Yo$ encuentro que son necesarios grupos en los que baya chicos y chicas, porque no tienen las mismas opiniones, esto puede bacer cosas bien (...)».

En el balance final, los alumnos dieron en seguida en el clavo al hablar del mayor error, evidente después, de la secuencia didáctica en relación a uno de los objetivos importantes a los ojos de los profesores: hacer que se encontraran e intercambiar alumnos de grupos y de «tipos» difèrentes. Tal y como estaba previsto el 
dispositivo, éste incitaba a la confrontación más que al intercambio, al enfrentamiento más que a la colaboración.

¿Qué se hubiera tenido que hacer? Dos alumnos proponen, si se hiciera otra experiencia de este tipo, ver los sketchs de forma separada, en el interior de cada clase. Otro va más lejos:

$\mathrm{Pa}$ (LM): «Hubiéramos tenido que estar las dos clases resueltamente mezcladas, no como allie en donde bay un lado $8^{\circ} \mathrm{GB}$ y un lado $8^{\circ} \mathrm{LMB}$. Si bubiéramos estado ambas mezcladas, bubiéramos tenido fácilmente la misma opinión».

Estas dos observaciones y sugerencias me llevan a definir objetivos alternativos para una experiencia similar: confrontación o integración, que pretendieran aprendizajes diferentes en el ámbito de las relaciones sociales.

En el primer caso, sería bueno empezar con grupos concebidos como legítimamente diferentes, separados por un cierto número de diferencias de puntos de vista, que darían lugar a una discusión. El objetivo no sería reducir estas divergencias sino delimitarlas mejor, matizarlas y hacerlas aceptar por cada grupo, que saldría reforzado de la operación en su identidad como grupo ... y tal vez más tolerante.

En el segundo caso, se buscará, por el contrario, minimizar las diferencias intergrupos para favorecer una colaboración que acercará alumnos supuestamente diferentes debido al hecho de su pertenencia social (en sentido amplio). Es posible que surjan una confrontaciones, pero con interequipos mixtos.

\section{VENTAJAS, LIMITES Y DEFECTOS DEL DISPOSITIVO DIDACTICO ADOPTADO}

Al final de este capítulo sobre los resultados de la experiencia, volvemos a una de las preguntas enunciadas al principio: ¿cuál es la eficacia, respecto a los objetivos propuestos, de un dispositivo que formula implícitamente la hipótesis de aprendizajes espontáneos e incidentales? Es decir, ¿`se puede enseñar de forma eficaz la lengua oral renunciando a intervenciones didácticas sistemáticas, que se organizan explícitamente en función de los objetivos definidos? $\mathrm{O}$ incluso, ¿es suficiente estructurar globalmente la situación de interacción para que la práctica de los intercambios de lenguaje desemboqun en un mejor dominio de la argumentación oral en un grupo? Se debe responder: sí, en parte, pero con una eficacia limitada e insuficiente en ciertos aspectos.

Como hemos visto, la regulación que interviene en las discusiones lleva a los alumnos que hacen uso de la palabra a precisar mejor el objeto y los criterios de su evaluación, a matizar sus apreciaciones (mediante preguntas, sugerencias) para que sean más aceptables. Son resultados no desdeñables, sobre todo si se tiene en cuenta el obstáculo que representaba para los intercambios el tamaño del grupo. Los progresos se deben, en parte, a la manera en que se organizó la secuencia y la discusión estructurada por los profesores, que se lanzaron a realizar una acción de envergadura, bastante poco corriente en la enseñanza cotidiana. En el ámbito de la pedagogía del texto (escrito $u$ oral) nuestra eficacia se debe, probablemente y entre otras cosas, a nuestra capacidad para imaginar y poner en práctica proyectos en los que los alumnos se encuentran en situación funcional de comunicación: en las que están motivados para expresarse; en las que el objeto de aprendizaje (el género de texto o de actividad de lenguaje) es relativamente homogóneo y constituye un objetivo claro (argumentación oral sobre evaluaciones); en las que disponen de suficiente tiempo (en nuestro caso, 8 sesiones de 45 minutos) para asimilar los conocimientos o los savoir-faire que se persiguen; en las que el mismo ejercicio de una actividad se muestra estructurante gracias a los feed-back que implica. 
Pero, lo hemos constatado, el dispositivo adoptado estaba lejos de ser ideal. El tamaño del grupo y la ausencia de intervenciones didácticas explican probablemente los resultados menos satisfactorios o poco satisfactorios en muchos ámbitos. En un primer lugar, la no participación en las discusiones de una buena cuarta parte de los alumnos. Los progresos apuntados anteriormente son pues únicamente los de una parte de los alumnos. Para los que han permanecido mudos es imposible evaluar el impacto de la experiencia. En todo caso, uno de los objetivos del principio no se consiguió: favorecer el uso de la palabra de los alumnos que normalmente no se expresan. Nos parece demasiado fácil explicar este tipo de resultado mediante la intervención de factores afectivos personales, difícilmente modificables. No se dió a estos alumnos la oportunidad, ni sobre todo los medios, para expresarse: no «desmontamos», para ellos en especial, lo que es una evaluación, cómo y de qué maneras puede ser expresada.

Al hacerlo, hubiéramos podido llevar un poco más lejos el dominio de la competencia argumentativa, tal y como la hemos descrito en las páginas anteriores. Enseñando, por ejemplo, las diferentes maneras de modular o modalizar una apreciación para que sea aceptable; haciéndoles analizar, por qué ciertas evaluaciones parecen mejor fundamentadas (aceptables o discutibles) que otras, gracias a diversas formas de justificaciones; mostrando algunas formas de lenguaje útiles o prácticas para formular la aprecicación o la justificación, para introducir una réplica o un contraargumento.

Por último, sumado a un dispositivo inadecuado porque inducía a la confrontación, la perspectiva no-intervencionista adoptada no facilitó los aprendizajes de tipo socio-afectivo y sociolingüístico. El análisis de las estrategias de unos y otros, así como de los criterios implícitos sobre los cuales se basan sus evaluaciones, hubiera podido contribuir a una desdramatización de la situación y a una mejor percepción y comprensión por parte de los alumnos de los mecanismos en juego.

\section{¿Y SI SE HUBIERA DE HACER NUEVAMENTE?}

A modo de discusión y conclusión, vamos a esbozar brevemente algunas sugerencias para una nueva experiencia del mismo tipo. Para ello, nos basaremos en los trabajos llevados a cabo desde hace varios años por un comité paritario que reune profesores e investigadores (cf. Commission Pédagogie du texte, 1985, 1988), y en una concepción pedagógica que poco a poco ha ido emergiendo.

En pocas palabras, nuestro trabajo con los alumnos sea guía por tres principios. Intentamos:

- inscribir las actividades propuestas a los alumnos en un proyecto de clase (objetivo, finalidad que sobrepasaba a menudo la enseñanza del francés);

- estructurar los aprendizajes en una secuencia didáctica que incluye uno o varios módulos del modelo presentado en el cuadro ${ }^{\circ} 1$;

- referirnos a un modelo del funcionamiento de los discursos para la elección de las actividades de lenguaje que tienen que ejercitarse, el análisis de las dificultades de los alumnos y el tipo de remedios que se les propone.

La experiencia de la cual hemos dado cuenta incluía sobre todo el proyecto, para la clase, de preparar sketchs en video y, con este propósito, de iniciarse al manejo de la cámara. En una nueva experiencia, este tipo de objetivo podría ser conservado tal cual. Observemos que el intercambio entre alumnos - y el entrenamiento en la argumentación que resulta del mismo - son objetivos derivados pero centrales desde el punto de vista de la enseñanza del francés. Por otra parte, para nosotros, no es de lamentar que el proyecto mismo no sea de naturaleza lingüística. De este modo, las 
actividades de lenguaje se situan en un lugar que a menudo es el suyo: el de medio para conseguir otro fin. En este caso, la discusión y las evaluaciones deberían servir para mejorar la competencia de los alumnos en dos ámbitos a la vez: la elaboración y la realización de películas de video y el manejo de la argumentación. La integración de las actividades de lenguaje en el conjunto de las actividades materiales y sociales corresponde bien a nuestra concepción teórica del lenguaje y del discurso (cf. Bronckart y cols., 1985, cap.1).

\section{TABLA I}

Esquema de principio del módulo de una secuencia didáctica en pedagogía del texto

- Evaluación (encuesta y motivación previas; pretest/pretexto durante la primera fase)

- Elaboración del contenido y de la forma

-Elaboración de la situación de producción / comunicación

-Redacción o producción oral

- Evaluación: formativa o sumativa según la etapa de la secuencia

En el marco de este artículo, y por falta de espacio, no diremos prácticamente nada del modelo que utilizamos (cf. Bain, 1987). En cambio, nos referiremos a las diferentes etapas de una secuencia y de un módulo didácticos para estructurar las propuestas concretas que serán esbozadas brevemente en las siguientes líneas.

Los dos primeras películas y las dos primeras sesiones, debidamente grabadas, podrían ser utilizadas para la fase de evaluación. A partir de extractos de grabaciones, el profesor señalará los aspectos problemáticos: malas identificaciones del objeto de la evaluación; apreciaciones poco explícitas o formuladas de forma molesta; justificación ausente o inadecuada; críticas que ignoran sistemáticamente ciertos aspectos de la producción.

También se deberían explotar de forma positiva estos primeros intercambios para mostrar producciones argumentativas-evaluativas satisfactorias, especialmente bien acogidas, que proporcionan ejemplos de evaluaciones explícitas; críticas aceptables para el destinatario y útiles para continuar las operaciones (preguntas, sugerencias); justificaciones pertinentes; análisis de la película sobre aspectos ignorados en general (técnica de realización, adecuación guión - condiciones de rodaje). De este modo, se podría reconstruir con los alumnos el esquema de Meux (figura 4 presentada anteriormente); precisar para cada punto de este esquema (mediante ejemplos tipo) las cualidades a conseguir y los obstáculos a evitar; completar mediante una lista, aspectos a seleccionar para el análisis y las justificaciones; dirección y realización, decorados; coherencia, organización y originalidad del guión; representación de los actores; técnica de video, adecuación entre el medio y el guión. Todo esto podría concretarse en una «lista de control» hecha por los alumnos, que ilustrara y especificara las exigencias y los objetivos que se quieren conseguir.

Esta fase presenta múltiples ventajas desde el punto de vista didáctico. Permite precisar la continuación de las operaciones centrándose en los aspectos más problemáticos para el grupo de alumnos concernido; disponer en serie las prioridades en los objetivos a alcanzar; formular hipótesis sobre el origen de las dificultades de los alumnos y preparar los remedios tópicos necesarios (estrategia de evaluación formativa). Ésta indica específicamente a los alumnos el tipo de dominio que se quiere alcanzar. Les muestra que tomamos en serio sus producciones, que éstas pueden servir como referencia a la enseñanza y ser utilizadas como puntos de partida o motores de progreso (lo que no impide el recurso a otras producciones modelos). Fase metacognitiva que enseña, además, a los alumnos a reflexionar sobre sus acciones y sobre su funcionamiento. 
En este caso, las actividades descritas en la fase de evaluación rebasan ya hacia las etapas siguientes de elaboración del contenido y de la forma. Pero éstas constarán de otros ejercicios, diseñados según nuestros propósitos, que enseñarán a los alumnos a partir de una película corta, a formular oralmente o por escrito ciertas críticas en una forma más o menos canónica (en este estadio, no debe temerse a la estereotipia). También, se puede hacer que escuchen y critiquen una discusión entre adultos sobre un tema parecido (análisis de una película), señalando y escudriñando algunos episodios evaluativos mediante el esquema de Meux. La característica capital de todos estos ejercicios es la de situarse en el interior y al servicio del proyecto pedagógico más general (sobre todo de las próximas etapas de la secuencia), siempre en una perspectiva textual y comunicativa global.

Una situación de comunicación-juego como la descrita en el documento de A. Pasquier y N. Steffen (1988) ${ }^{11}$, en la que los alumnos dan oralmente a sus compañeros instrucciones para realizar una construcción con piezas de Lego, es útil si aparecen al principio o a lo largo de la secuencia, dificultades de descentración (tomar en cuenta las características del destinatario o de la situación de recepción) y de gestión de lo implícito. Este mismo tipo de ejercicio ejercitado sin más me parece, en cambio, que participa del artilugio didáctico, artificial, divertido en el momento, pero sin gran transferabilidad ni eficacia a largo plazo. En efecto, el alumno no lo relacionará con otras situaciones que necesiten descentración y explicitación.

En la fase de elaboración de la situación de producción (que puede haber sido iniciada con anterioridad), se insistirá en ciertos aspectos del discurso poligestionado (cuya gestión depende de los interlocutores presentes), en las características de un verdadero intercambio por oposición a monólogos yuxtapuestos en los que cada cual «arroja» lo que tiene ganas de decir sin ocuparse de los demás. Para ello, se puede recurrir a algunos extractos de grabaciones, por ejemplo de ciertas mesas redondas en la Televisión suiza de habla francesa (TVSR), ipara los buenos y los malos ejemplos! De nuevo, se llevarán a cabo ciertas selecciones a partir de los principales objetivos de la secuencia y de los problemas señalados en la fase de evaluación. Por ejemplo, nos podríamos centrar en la contra-argumentación, la refutación; eventualmente evocar las modificaciones que introduciría un cambio de situación (Ejemplo: alumnos presentando y defendiendo su película de video en la TVSR o ante un grupo de padres: modificación de los destinatarios y del lugar social). Dicha simulación sería probablemente beneficiosa, aunque sólo fuera para tomar conciencia de las características de la situación habitual (lugar social escolar, alumnos co-productores del discurso, registros de lenguaje inducidos, tipos de modalizaciones utilizadas, objetivos y posturas, etc.). Sería en esta etapa cuando se podrían abordar ciertos problemas socioafectivos y ciertas estrategias de discusión.

La continuación de la secuencia corresponderá a la siguiente fase de producción de lenguaje, abandonando la siruación especial del ejercicio para sumergirse de nuevo en la actividad compleja de discusión libre. La última sesión se consagrará a un balance, que explotará, preferentemente, un análisis de las últimas discusiones para mostrar los progresos conseguidos o los que quedan por conseguir (comparación con los objetivos y recurso a la lista de control como referencias).

No he abordado - y no abordaré - el problema de la individualización en el aprendizaje de la comunicación oral. El dispositivo descrito anteriormente induce una cierta diferenciación de las intervenciones del maestro. La lista de control, utilizada como pauta de evaluación formativa permite sobre todo indicar a cada alumno, en el momento de los balances intermedios, los aspectos en los que debería fijarse y esforzarse. Me parecería prematuro tratar de ir más lejos en las propuestas mientras que problemas primordiales no hayan sido resueltos: por ejemplo, la elección de objetivos y perspectivas metodológicas, o la elaboración de un repertorio de ejerci- 
cios diversificados. En este estadio, se tendría que procurar que las opciones convengan al más amplio abanico de alumnos. Creo que una diferenciación más profunda sería objeto de un estadio posterior de la investigación. En el ámbito de la pedagogía de la lengua oral, la tarea es demasiado amplia para que pretendamos abarcar todos los problemas a la vez.

\section{Notas}

1. NdT. «Le Cycle d'Orientation» de Ginebra corresponde más o menos a B.U.P. En la época de la investigación, el «Cycle d'Orientation» tenía tres especialidades distintas: Científico, Moderno-Latino y General. Los alumnos son seleccionados al entrar en función de las notas sacadas anteriormente. Según la rama donde se les ubica, los alumnos podrán ir posteriormente al «Collège» y luego a la Universidad (los que están en Científico y en Moderno-Latino) o a Formación profesional (los que están en General). El «Cycle d'Orientation» supone pues, una gran selección de los alumnos.

2. "Como además, la selección escolar, en los niveles primario y secundario, descansa principalmente en una cierta habilidad a manejar el lenguaje, me dije que la experiencia que ibamos a intentar permitiría probablemente que los alumnos de General se sientieran finalmente valorizados en relación con sus compañeros de Latino-Moderno: el ejercicio que proponíamos priorizaba, en efecto, en un primer momento, los elementos visuales; en un segundo momento, la discusión oral» (Boget y cols., 1977, p.6).

3. NdT. Traducimos «boguet» por «amotillo» (motocicleta), intentando acercarnos lo más posible al lenguaje de los adolescentes.

4. NdT Hemos intentado traducir los ejemplos conservando las mismas características (lengua oral) con las que fueron producidos en francés.

5. Meux distingue todavía dos categorías: aplicación de reglas y examen de las consecuencias, que no corresponden a ninguna de las críticas encontradas en nuestras observaciones.

6. Más adelante se constatará que esta clasificación, aparentemente satisfactoria a nivel cognitivo, no es realmente adecuada para juzgar la competencia comunicativa a nivel socio-afectivo.

7. Por razones puramente prácticas, hemos renunciado, más de diez años después, a hacer nuevamente el análisis de nuestros datos (episodios evaluativos) a partir de nuevos criterios.

8. Precisemos que la discusión no fue en absoluto informal, habida cuenta de las restricciones prácticas del gran grupo y la disciplina que implica cualquier actividad en clase.

9. Esta lectura de las discusiones entre los alumnos nos es sugerida por los trabajos de Bernstein (1972), sin que adheramos a la descripción que hace de los dos códigos lingüísticos (más bien sociolingüísticos) claramente distintos.

10. Puede ser un poco abusivo atribuir a toda una clase, la opinión de algunos de sus miembros; sin embargo, ciertos alumnos que tomaron la palabra parecen haber tenido un rol de líderes y su opinión expresa probablemente ciertas normas y valores del grupo.

11. Tomado de Grisay y Delansdheere (1979).

\section{Referencias}

BACH, P. (1987) L'écriture buissonnière. Pédagogie du récit, Neuchâtel-París, Delachaux y Niestlé

BAIN, D. (1987) «D'une typologie à une didactique du texte», Enjeux, 11, pp. 49-68

BAIN, D. y HeXEL, D. (1977) Observation d'une expérience vidéo. Analyse des discussions entre deux classes (8e LM et G), Ginebra, Centre de recherches psychopédagogiques du Cycle d'orientation

BaIN, D. y SCHNEUwLY, B. (1987) «Vers une pédagogie du texte», Le français aujourd'bui, 79, pp. 1323

BERNSTEIN, B. (1972) Class, codes and control, Vol. 3, Towards a theory of educational transmissions, Londres, Routledge y Kegan

Boget, E.; Truan, F.; BaIN, D. y HeXel, D. (1977) Français: utilisation de la vidéo dans l'apprentissage de la discussion. Présentation d'une expérience, Ginebra, Centre de recherches psychopédagogiques du Cycle d'orientation

Bronckart, J.-P.; Bain, D.; SChNeuWly, B.; Davaud, C. y Pasquier, A. (1985) Le fonctionnement des discours. Un modele psychologique et une méthode d'analyse, Neuchâtel-París, Delachaux y Niestlé

Commission pédagogie du texte (1988) Contributions à la pédagogie du texte II, Ginebra, Faculté de Psychologie et Sciences de l'Education, Cahier $\mathrm{n}^{\circ} 52$

GRISAY, A. (1979) 50 situations de communication pour l'apprentissage de l'expression wrale dans l'enseignement fondamental, Lieja, Université de Liège, Laboratoire de pédagogie expérimentale 
Grisay, A. (1983) «Didier et Anne. Présentation de deux dialogues d'enfants en situation de communication", Revue de la Direction générale de l'organisation des Etudes du Ministère de l'Education nationale, 2, pp. 9-22

MEUX, M. (1963) «The evaluation Operations in the Classroom», en Bellak, A.A. (Ed.) Theory and Research in Teaching, Nueva York, The Teachers College Press, Teachers College, Columbia University, pp. 11-24

PASQUIER, A. y STEFFEN, N. (1988) Recherche développement sur l'expression et la communication orales, Ginebra, Service de la recherche sociologique

PERrENOUD, Ph. (188) A propos de l'oral, Ginebra, Service de la recherche sociologique

ROЛleT, E. (1991) «La pédagogie de l'oral en question(s)», en Wirthner, M.; Martin, D. y Perrenoud, Ph. (Eds) Parole étouffée, parole libérée. Fondements et limites d'une pédagogie de l'oral, Neuchâtel-París, Delachaux y Niestlé, pp. 41-54

\section{Anexo \\ RESUMEN DE LOS SKETCHS ELABORADOS Y FILMADOS EN VIDEO POR LOS ALUMNOS}

\section{1) Orquesta retro (LM)}

¡Músicos vestidos a la moda de 1920 tocan una música difícilmente identificable dada la ausencia de sonido! Se supone que el contrabajista debe manifestar su oposición al tipo de música que ejecuta.

\section{2) Investigación sobre un robo $(\mathrm{G})$}

Desde su ventana, una mujer observa en un apartamento vecino, el robo de un objeto que no puede identificar. El inspector encargado de la investigación juega a ser Sherlock Holmes, al examinar las cenizas de los cigarrillos. Persuadido de que se trata de un importante robo de joyas, se imagina ya cubierto de gloria y de fortuna gracias a este caso y gozando de un descanso bien merecido en una isla lejana. Desgraciadamente, el ladrón (que arrestan cuando vuelve a buscar un paquete de cigarrillos que había olvidado) sólo había hurtado un salero y los sueños del comisario se derrumban brutalmente.

\section{3) Proceso de un secuestrador (G)}

Un desequilibrado rapta a un niño y lo mata. Asistimos a su proceso y a su ejecución en la horca. Algunos años después, su cadáver (el esqueleto del material de ciencias naturales) sigue colgado en la horca.

\section{4) El marido versátil (LM)}

En un parque, una pareja se sienta en un banco. La señora se duerme y el marido hace la corte a una bonita rubia, con la que se va. Son perseguidos por la mujer legítima que les amenaza con un rodillo de cocina pero se enreda con su vestido largo y se cae (sketch dirigido como una película de Charlot).

\section{5) Cómo desembarazarse de un inoportuno (LM)}

En un compartimento abarrotado, un campesino, presentado como un personaje grosero, importuna a los viajeros. Para desembarazarse de él, una mano maliciosa y criminal cambia los letreros "WC" $\mathrm{y}$ "SALIDA» justo antes de que el inoportuno vaya a satisfacer una necesidad natural y urgente. ¡Adiós al campesino!

\section{6) Los hinchas (G)}

Dos generaciones de hinchas asisten a un partido de fútbol. Los jóvenes espectadores de la segunda fila despliegan una pancarta, fuman, gritan, se agitan y se granjean las observaciones de los «vejestorios» de la primera fila. La discusión se convierte finalmente en una pelea general.

\section{7) Homicidio en un tren (G)}

En un compartimento, se comete un homicidio en el momento en el que tren pasa por un túnel, pero el criminal, que había echado el ojo a una mujer cargada de joyas, se equivoca de víctima. A su vez, el inspector (?) se equivoca de culpable, deteniendo a la mujer de las joyas 
que posee un revólver, cuando la víctima ha sido estrangulada. La última escena revela al espectador la verdadera culpable en la persona de una falsa ciega.

8) La partida de cartas (LM)

Cuatro personajes en torno a una mesa de juego juegan a cartas. La camarera va a preguntar lo que desean tomar. Uno de los jugadores le hace proposiciones que ella rechaza momentáneamente. Una jugadora (una chica negra) intenta en vano integrarse al juego. La partida acaba, la camarera se va con su amor. Las cartas dibujan sobre la mesa la palabra FIN.

\section{Problemas psicopedagógicos de la lengua oral: las lecciones de una experiencia Daniel Bain$$
\text { CL\&E, 1994, 22, pp. 91-115 }
$$

Resumen: El artículo plantea algunas preguntas inspiradas en una experiencia educativa y, más concretamente, en la actividad de un grupo de profesores e investigadores que trabajan sobre el tema de la pedagogía del texto. Después de algunas observaciones a modo de introducción, se presentan la evolución y los resultados de una secuencia didáctica, dirigida a adolescentes de 13-14 años, que tiene por objeto la argumentación oral. Se incluyen también algunos comentarios ampliando el tema a los problemas encontrados en la enseñanza de la lengua oral en general.

Artículo original: «Problèmes psychopédagogiques de l'oral: Les leçons d'une expérience». En Writhner, M.; Martin, D. y Perrenoud, Ph (Eds.) (1991). Parole étoufflée, parole libérée. Fondements et limites d'une pédagogie de l'oral. Neuchâtel-París, Delachaux y Niestlé, pp. 95-125. Reproducido con autorización de Editions Delachaux et Niestlé. Traducción de Mercè Pujol y Mercè Cartié. Nuestro agradecimiento a Roser Vendrell y Ricarda Steffen por las correcciones efectuadas al presente manuscrito.

Datos sobre el autor: Daniel Bain trabaja en el Centro de Investigaciones Psicopedagógicas de Ginebra. Dirije desde hace mucho años un equipo de investigación compuesto de forma paritaria por profesores e investigadores. Es autor de numerosos artículos y libros sobre didáctica de la lengua.

Dirección: Centre de Recherches Psychopédagogiques, Collège de Coudriers, $15 \mathrm{~A}$ Av. JoliMont, C.P. 218, CH - 1211 Ginebra 28, Tel. 07-41-22-98.50.20

(C) PERMISOS PARA CITAR O REPRODUCIR EN OTRAS FUENTES: Se pueden citar libremente hasta 500 palabras. Para reproducir una porción de texto mayor, figuras o ilustraciones, se deberá pedir permiso por escrito a la revista, especificando el uso al que se destina el texto. En todos los casos, se deberá citar el copyright de CL\&E. En el caso de artículos o textos que hayan sido a su vez reproducidos en $C L \& E$ los interesados deberán dirigirse tanto a los detentadores del copyright original como a $C L \& E$, en el caso de que se quiera hacer uso de la traducción. FOTOCOPIAS: Para todo lo relacionado con el uso mediante fotocopia del material de esta revista, deberán dirigirse a: CEDRO, C/ José Marañón, 10, 3. ${ }^{\circ}$ Izda. Tel. 5941575 . Fax 4453567 